\title{
Bioprosthetic or mechanical heart valves: prosthesis choice for borderline patients? - Results from 9,616 cases recorded in Polish national cardiac surgery registry
}

\author{
Krzysztof Bartus ${ }^{1}$, Radosław Litwinowicz ${ }^{1}$, Jerzy Sadowski ${ }^{1}$, Grzegorz Filip ${ }^{1}$, Mariusz Kowalewski ${ }^{2}$, \\ Piotr Suwalski ${ }^{2}$, Piotr Mazur ${ }^{1}$, Anna Kędziora ${ }^{1}$, Marek Jasiński ${ }^{3}$, Marek Deja ${ }^{4}$, Mariusz Kuśmierczyk ${ }^{5}$, \\ Pawel Czub $^{6}$, Michal Zembala ${ }^{7,8}$, Marek Jemielity ${ }^{9}$, Rafał Pawlaczyk ${ }^{10}$, Zdzisław Tobota ${ }^{11}$, \\ Bohdan Maruszewski $^{11}$, Boguslaw Kapelak ${ }^{1}$
}

${ }^{1}$ Department of Cardiovascular Surgery and Transplantology, Jagiellonian University, John Paul II Hospital, Krakow, Poland; ${ }^{2}$ Clinical Department of Cardiac Surgery, Central Clinical Hospital of the Ministry of Interior and Administration, Warsaw, Poland; ${ }^{3}$ Department of Cardiac Surgery, University Hospital in Wroclaw, Wroclaw Medical University, Wroclaw, Poland; ${ }^{4}$ Department of Cardiac Surgery, Medical University of Silesia, Katowice, Poland; ${ }^{5}$ Department of Cardiosurgery and Transplantology, The Cardinal Stefan Wyszynski Institute of Cardiology, Warsaw, Poland; ${ }^{6}$ Department of Cardiac Surgery, Medical University of Warsaw, Warsaw, Poland; ${ }^{7}$ Silesian Center for Heart Disease, Zabrze, Poland; ${ }^{8}$ Department of Cardiac Surgery, Vascular Surgery and Transplantology Silesian Medical University Katowice, Katowice, Poland; ${ }^{9}$ Department of Cardiac Surgery and Transplantology, University Hospital of Lord Transfiguration, Poznan University of Medical Sciences, Poznan, Poland; ${ }^{10}$ Department of Cardiac Surgery, Medical University of Gdansk, Gdansk, Poland; ${ }^{11}$ Department for Pediatric Cardiothoracic Surgery, Children's Memorial Health Institute, Warsaw, Poland

Contributions: (I) Conception and design: K Bartus, R Litwinowicz; (II) Administrative support: R Litwinowicz, P Mazur, A Kedziora, G Filip; (III) Provision of study materials or patients: M Kowalewski, G Filip, M Jasinski, M Dejak, M Kusmierczyk, S Pawlak, M Jemielity, D Jagielak, P Hendzel, P Suwalski, Z Tobota, B Maruszewski, B Kapelak; (IV) Collection and assembly of data: All authors; (V) Data analysis and interpretation: All authors; (VI) Manuscript writing: All authors; (VII) Final approval of manuscript: All authors.

Correspondence to: Radoslaw Litwinowicz, MD, PhD. Department of Cardiovascular Surgery and Transplantology, Jagiellonian University, JP II Hospital, ul. Pradnicka 80, 31-202 Krakow, Poland. Email: md.litwinowicz@gmail.com.

Background: In middle-aged patients undergoing aortic valve replacement (AVR), the selection of prosthesis type is a complex process. Current guidelines do not unequivocally indicate the type of prosthesis (bioprosthetic or mechanical) recommended for patients between 60-70 years of age. The aim of the study was to present the trends in AVR prosthesis selection in borderline patients over a 10-year period, based on real-life registry data.

Methods: The study population comprised of 9,616 consecutive patients aged between 60-70 years, who underwent isolated AVR between 2006 and 2016 in all cardiac surgery departments in Poland. Data were extracted from the Polish National Registry of Cardiac Surgery.

Results: Among 27,797 consecutive AVR procedures, patients aged 60-70 years represented 34.6\% of the population operated on. From 2006 to 2016, bioprosthetic valves (BVs) were implanted in 53.9\% cases, (and) mechanical valves (MVs) in $42.1 \%$. The proportion of different valve types changed in time: from $77.5 \%$ of MVs vs. $22.5 \%$ of BVs in 2006 to $23.2 \%$ of MVs vs. $76.8 \%$ of BVs in $2016(\mathrm{P}<0.001)$. The most commonly implanted BV was the Hancock II (used in 36.4\% of BV implantations), the most commonly used MV was the Saint Jude Mechanical prosthesis (implanted in 36.4\% of MV implantation cases). A multivariable model identified smaller annulus [OR (95\% CI) 0.89 (0.86-0.92), $\mathrm{P}<0.001$ ], atrial fibrillation [OR (95\% CI) 1.32 (1.05-1.67), $\mathrm{P}=0.017$ ], male sex [OR (95\% CI) 1.47 (1.24-1.74), $\mathrm{P}<0.001]$ and year of implantation [OR (95\% CI) 0.75 (0.71-0.79), $\mathrm{P}<0.001]$ as predictors of $\mathrm{MV}$ implantation.

Conclusions: Patients aged 60-70 years represent more than one-third of all AVR patients. Between 2006 and 2016, the proportion of implanted prostheses has changed dramatically. In 2016 BVs were implanted in nearly $75 \%$ of AVR cases, three times more often than in 2006. 
Keywords: Mechanical prosthesis; biological prosthesis; valve; middle-age patients

Submitted Nov 04, 2019. Accepted for publication Jun 05, 2020.

doi: $10.21037 /$ jtd-19-3586

View this article at: http://dx.doi.org/10.21037/jtd-19-3586

\section{Introduction}

Middle-aged patients are healthier, have fewer comorbidities and a lower risk of operation compared to the older population. Therefore, in middle-aged patients surgical aortic valve replacement (AVR) is still the gold standard for treating aortic stenosis, while transcatheter aortic valve implantation (TAVI) is reserved for older patients, with higher risk for poor surgical outcome $(1,2)$.

The advantages and disadvantages of mechanical valves (MV) and bioprosthetic valves (BV) are well known (1-5). In middle-aged patients, both prosthesis-related factors and patient preferences should be taken into account, when choosing the type of valve prosthesis. Prosthesis selection is oftentimes difficult and requires a complex decision-making process, especially in patients aged between $60-70$ years. For this group of patients, the recommendations are vague or lacking. Current ESC/EACTS guidelines recommended a bioprosthesis in aortic position for individuals $<60$ years of age, while bioprosthesis is recommended in patients $>65$ years old (both, class IIa recommendation, level of evidence C) (1). AHA/ACC guidelines suggest MV selection for patients as young as $<50$ years of age (class IIa recommendation, level of evidence B) (2). Hence, prosthesis selection in patients aged $60-70$ years is backed with insufficient evidence, difficult, and made on case-by-case basis.

We present the following article in accordance with the 5-STROBE guideline checklist (available at http://dx.doi. org/10.21037/jtd-19-3586).

The aim of the study was to present time-related trends in elective surgical AVR in patients aged between 60-70 years old, based on 9,616 cases from a multicentre Poland registry. Ten-year trends were assessed by comparing patient characteristics, distribution of risk factors, aortic valve pathology, valve types, surgical outcomes, and inhospital mortality.

\section{Methods}

\section{Database}

The study was conducted in accordance with the
Declaration of Helsinki (as revised in 2013). This study used retrospective data from the obligatory Polish National Cardiac Surgery Database ("KROK" registry; www. krok.csioz.gov.pl). The Polish Society of Cardiothoracic Surgeons approved this project. All data has been anonymized, and the need to obtain individual patient consents has been waived. The registry is an ongoing, nationwide, multi-institutional registry of cardiosurgical procedures in Poland and an initiative of the Club of Polish Cardiac Surgeons in cooperation with the Polish Ministry of Health that commenced in 2006 and collects data from all 37 heart surgery centers in Poland (a list of contributing centers is provided in the Acknowledgment section at the end of the article). Centers enrolling patients into the KROK registry are required to transfer the data concerning every cardiac surgery to the central database in the National Centre for Healthcare Information Systems at the Ministry of Health and are financially liable for data integrity and completeness. A registry module for collecting the data regarding myocardial infarctions (MIs), hospitalizations due to unstable angina, subsequent revascularizations, strokes, and other complications was under construction at the time of analysis (6).

\section{Study databases}

A detailed questionnaire, defined according to standard definitions, including demographic data, previous medical history, on-admission physical findings, pharmacological management, and outcomes, was developed. Data were collected either at presentation or by physician review of the hospital records and were forwarded to the KROK registry. The forms were reviewed for clinical face validity and analytical internal validity. On the basis of the form of the National Registry of Cardiac Surgery (KROK), a computer database was built for statistical analysis.

\section{Study population and clinical variables}

Using the KROK database, we identified patients who underwent isolated AVR as the first cardiosurgical 


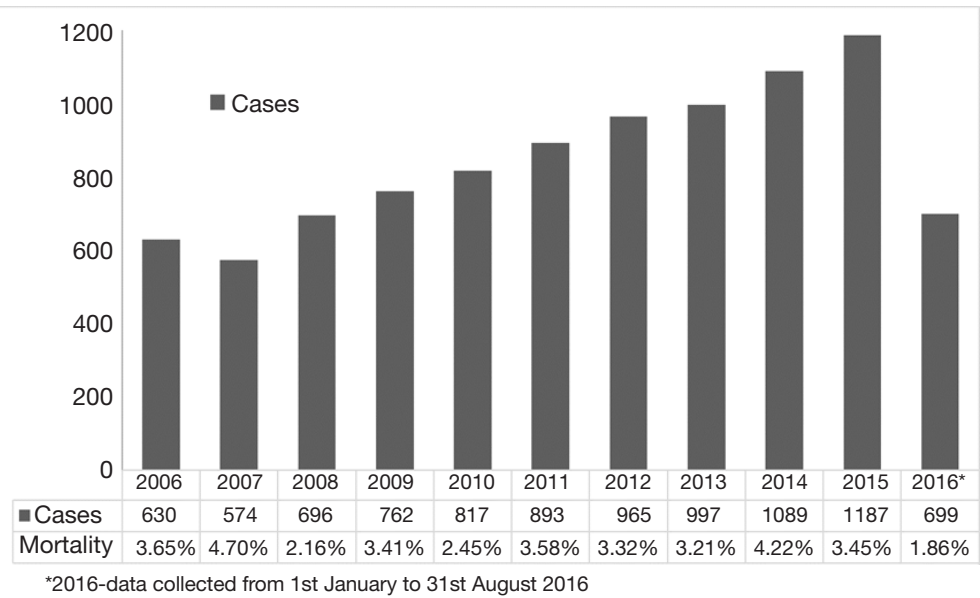

Figure 1 Number of cases and mortality of surgical AVR performed in each year.

intervention between January 2006 and August 2016. Patients who had previous cardiac surgery were excluded from the study. Among 27,97 consecutive adult patients who underwent isolated surgical AVR during the studied period 10,343 patients were aged between $60-70$ years $(37.2 \%)$. We excluded the records, where the type of prosthesis was not reported and not retrievable $(9.1 \%)$, resulting in a final cohort of 9,616 patients (34.6\%). For patients undergoing AVR, we collected: baseline demographic characteristics [age, gender, European system for cardiac operative risk evaluation (EuroSCORE) score, diabetes, body mass, hypertension, pulmonary hypertension, chronic kidney disease, extracardiac arteriopathy, chronic lung disease, left ventricle ejection fraction (LVEF), Canadian Cardiovascular Society, and New York Heart Association functional class], aortic valve pathology, preoperative aortic gradients, extracorporeal circulation time, aortic cross clamping time, time in the intensive care unit (ICU), total hospitalization time, in hospital mortality and time of death after surgery. In-hospital mortality was defined as death up to 30 days after the procedure. The authors had full access to the data, take responsibility for its integrity, and have read and agree to the manuscript as written.

\section{Statistical analysis}

Continuous variables were checked for normal distribution with the Kolmogorov-Smirnov test. Data expressed as mean \pm standard deviation or median (interquartile range), unless otherwise stated elsewhere. Categorical variables were expressed as count and percentage, and compared with the chi-square test. The consecutive years were treated as an ordinal variable and the Kolmogorov-Smirnoff test was performed to confirm the difference in the implanted valve type within consecutive years. The Poisson regression was created to estimate the impact of the consecutive years on the numerical amount of mechanical valves implantations represented as a percentage of total valve implantations within each year. Differences in age between patients each year were calculated using Friedman test, followed by posthoc Dunnett $\mathrm{C}$ analysis to assess the maximum differences. Multivariable regression model was created to confirm the independent impact of the surgery year on the implanted valve type. The model was standardized for EuroSOCRE I, sex, BMI, endocarditis as an indication for AVR, history of atrial fibrillation, and the size of the implanted valve as an expression of the annulus size. Statistical analysis was performed with STATISTICA 10.0 (StatSoft, Tulsa, OK, USA). A two-sided $\mathrm{P}$ value $<0.05$ was considered statistically significant.

\section{Results}

\section{Patient characteristics}

A total of 9,616 patients aged between $60-70$ years were studied. The caseload increased significantly from 630 cases performed in 2006 to 1,184 cases performed in 2015 (Figure 1). Detailed patient characteristics are presented in Table 1. From 2006 to 2016, BVs were implanted in 53.9\% cases, MVs in $42.1 \%$ cases. Regarding BVs, $89.5 \%$ of implanted prostheses were stented valves. There were no differences in mean transaortic gradients between BV and MV groups. The most common aortic valve pathology for both groups 
Table 1 Patient characteristics, valve pathology and operative data

\begin{tabular}{|c|c|c|c|}
\hline Variables & Biological $(\mathrm{n} / \mathrm{N}=5,191 / 5,191)^{\star}$ & Mechanical $(n / N=4,425 / 4,425)^{*}$ & $P$ \\
\hline Gender & & & 0.005 \\
\hline Female & $41.1 \%(2,133 / 5,191)$ & $37.6 \%(1,664 / 4,425)$ & \\
\hline Male & $58.9 \%(3,058 / 5,191)$ & $62.4 \%(2,761 / 4,425)$ & \\
\hline Euro SCORE & $1.8(0.8 / 1.8)(5,191 / 5,191)$ & $1.4(0.7 / 1.4)(4,425 / 4,425)$ & 0.0001 \\
\hline LVEF (\%) & $55(48 / 60)(4365 / 5,191)$ & $55(48 / 60)(3,509 / 4,425)$ & 0.2369 \\
\hline $\operatorname{ccs}$ & & & 0.0071 \\
\hline $\operatorname{ccs} 0$ & $26.3 \%(1,599 / 5,086)$ & $30.7 \%(1,341 / 4,370)$ & \\
\hline $\operatorname{ccs} 3$ & $7.4 \%(449 / 5,086)$ & $7.8 \%(342 / 4,370)$ & \\
\hline $\operatorname{ccs} 4$ & $0.1 \%(45 / 5,086)$ & $1.4 \%(61 / 4,370)$ & \\
\hline NYHA & & & 0.0045 \\
\hline NYHA 0 & $4.5 \%(230 / 5,118)$ & $3.4 \%(149 / 4,371)$ & \\
\hline NYHA 1 & $9.9 \%(507 / 5,118)$ & $8.8 \%(383 / 4,371)$ & \\
\hline NYHA 2 & $47.1 \%(2,417 / 5,118)$ & $47.7 \%(2,087 / 4,371)$ & \\
\hline NYHA 3 & $34.6 \%(1,772 / 5,118)$ & $35.2 \%(1,538 / 4,371)$ & \\
\hline NYHA 4 & $3.6 \%(185 / 5,118)$ & $4.7 \%(204 / 4,371)$ & \\
\hline Chronic lung disease & $7.3 \%(361 / 4,975)$ & $6.7 \%(516 / 4,218)$ & 0.304 \\
\hline Diabetes insulin dependent & $7.1 \%(362 / 5,089)$ & $6.6 \%(290 / 4,381)$ & 0.3651 \\
\hline \multicolumn{4}{|l|}{ Renal impairment } \\
\hline Normal (CC >85 mL/min) & $59.6 \%(1,835 / 3,081)$ & $59.3 \%(881 / 1,486)$ & \\
\hline Moderate $(\mathrm{CC}>50$ \& <85) & $36.1 \%(186 / 3,081)$ & $35.3 \%(525 / 1,486)$ & 0.1786 \\
\hline Severe $(C C<50)$ & $3.9 \%(119 / 3,081)$ & $4.4 \%(66 / 1,486)$ & \\
\hline Dialysis (regardless of CC) & $0.5 \%(14 / 3,081)$ & $0.9 \%(14 / 1,486)$ & \\
\hline Pulmonary hypertension & & & 0.334 \\
\hline Severe (>55 mg) & $0.9 \%(28 / 3,087)$ & $1.1 \%(16 / 1,520)$ & \\
\hline Moderate $(31-55 \mathrm{mmHg})$ & $6.0 \%(186 / 3,087)$ & $5.0 \%(76 / 1,520)$ & \\
\hline None & $93.1 \%(2,873 / 3,087)$ & $93.9 \%(1,428 / 1,520)$ & \\
\hline
\end{tabular}

Table 1 (continued) 
Table 1 (continued)

\begin{tabular}{|c|c|c|c|}
\hline Variables & Biological $(n / N=5,191 / 5,191)^{\star}$ & Mechanical $(\mathrm{n} / \mathrm{N}=4,425 / 4,425)^{\star}$ & $P$ \\
\hline Smoking & & & 0.4521 \\
\hline Active smoker & $10.2 \%(513 / 5,037)$ & $9.9 \%(415 / 4,201)$ & \\
\hline Former smoker & $41.8 \%(2,107 / 5,037)$ & $40.8 \%(1,715 / 4,201)$ & \\
\hline Max. aortic gradients $(\mathrm{mmHg})$ & $85(70 / 100)(4,076 / 5,051)$ & $86(69 / 100)(3,353 / 4,425)$ & 0.1025 \\
\hline Implant prosthesis size & & & 0.0001 \\
\hline $17 \mathrm{~mm}$ & $0.02 \%(1 / 5,149)$ & $0.2 \%(11 / 4,225)$ & \\
\hline $19 \mathrm{~mm}$ & $3.5 \%(181 / 5,149)$ & $10.5 \%(442 / 4,225)$ & \\
\hline $25 \mathrm{~mm}$ & $21.3 \%(1,096 / 5,149)$ & $18.3 \%(773 / 4,225)$ & \\
\hline $27 \mathrm{~mm}$ & $8.0 \%(412 / 5,149)$ & $5.8 \%(247 / 4,225)$ & \\
\hline $29 \mathrm{~mm}$ & $2.3 \%(121 / 5,149)$ & $1.7 \%(70 / 4,225)$ & \\
\hline $31 \mathrm{~mm}$ & $0.06 \%(3 / 5,149)$ & $0.4 \%(15 / 4,225)$ & \\
\hline $33 \mathrm{~mm}$ & $0.02 \%(1 / 5,149)$ & $0.02 \%(1 / 4,225)$ & \\
\hline ECC time (min) & 93 (77/117) $(5,029 / 5,191)$ & 97 (79/122) (4,333/4,425) & 0.0001 \\
\hline $\operatorname{ACC}(\min )$ & $65(54 / 81)(4,109 / 5,191)$ & $97(79 / 122)(4,333 / 4,425)$ & 0.0001 \\
\hline Time on ICU (day) & $2(1 / 2)(4,927 / 5,191)$ & $2(1 / 3)(4,223 / 4,425)$ & 0.8700 \\
\hline
\end{tabular}

*, $(\mathrm{n} / \mathrm{N})$ : number of records/total number of available records. ACC, Aortic Cross Clamp; BMI, body mass index; CC, creatinine clearance; CCS, Canadian Cardiovascular Society; COPD, chronic obstructive pulmonary disease; ECC, extracorporeal circulation; NYHA, New York Heart Association.

was degenerative aortic stenosis. The proportion of prosthetic valves changed throughout time from $77.5 \%$ of MVs vs. $22.5 \%$ of $\mathrm{BVs}$ in 2006 , to $23.2 \%$ of MVs vs. $76.8 \%$ of BVs in $2016(\mathrm{P}<0.001$; Figure 2). The most commonly implanted prosthesis size was $23 \mathrm{~mm}$ in both groups. Prosthesis size $\leq 19 \mathrm{~mm}$ was observed in $3.5 \%$ cases of $\mathrm{BV}$, and in $10.7 \%$ cases of MV implantation $(\mathrm{P}<0.001)$. The most common bioprosthesis was the Hancock II implant, used in $36.4 \% \mathrm{BV}$ cases, and the most commons mechanical prosthesis was Saint Jude Mechanical implant, used in $42.4 \%$ (Figure 3). There were no differences between BV and $\mathrm{MV}$ in in-hospital mortality over the analysed period of time within each consecutive year.

The MV was implanted more often in case of a smaller annulus, atrial fibrillation, and male sex. The odds of MV implantation decreases decreased by almost $25 \%$ each year, regardless of other significant factors (Figure 4).

\section{Discussion}

Aortic valve surgery is the second most common type of cardiac surgery in Poland and worldwide, and with the ageing of the population, it is anticipated that the number of surgical AVR procedures, despite the progress of 


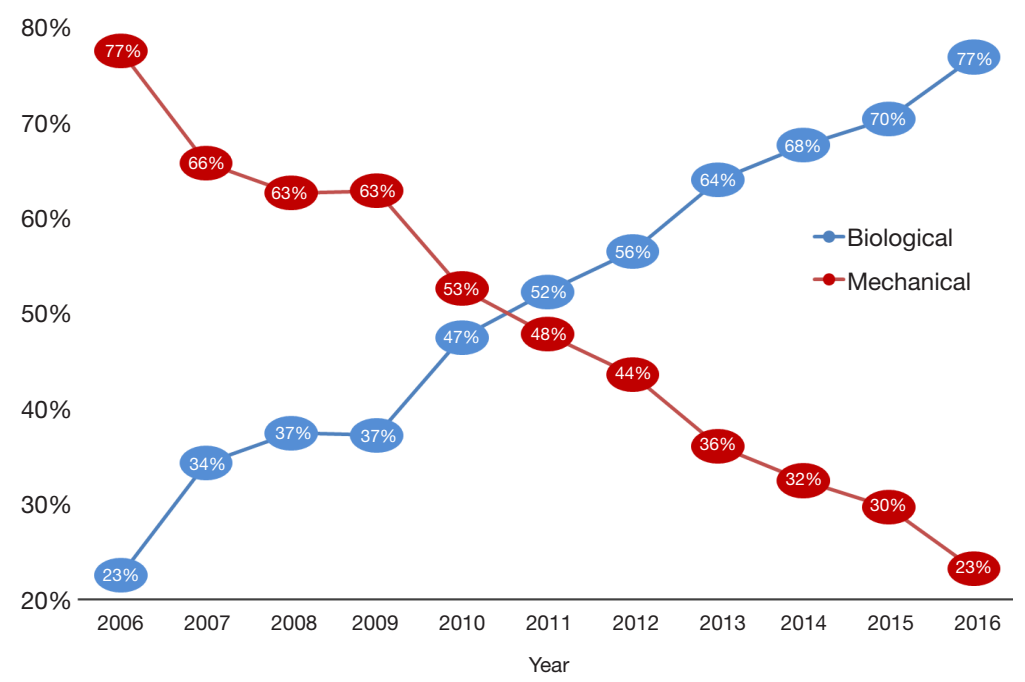

Figure 2 Type of prosthesis implanted in each year.
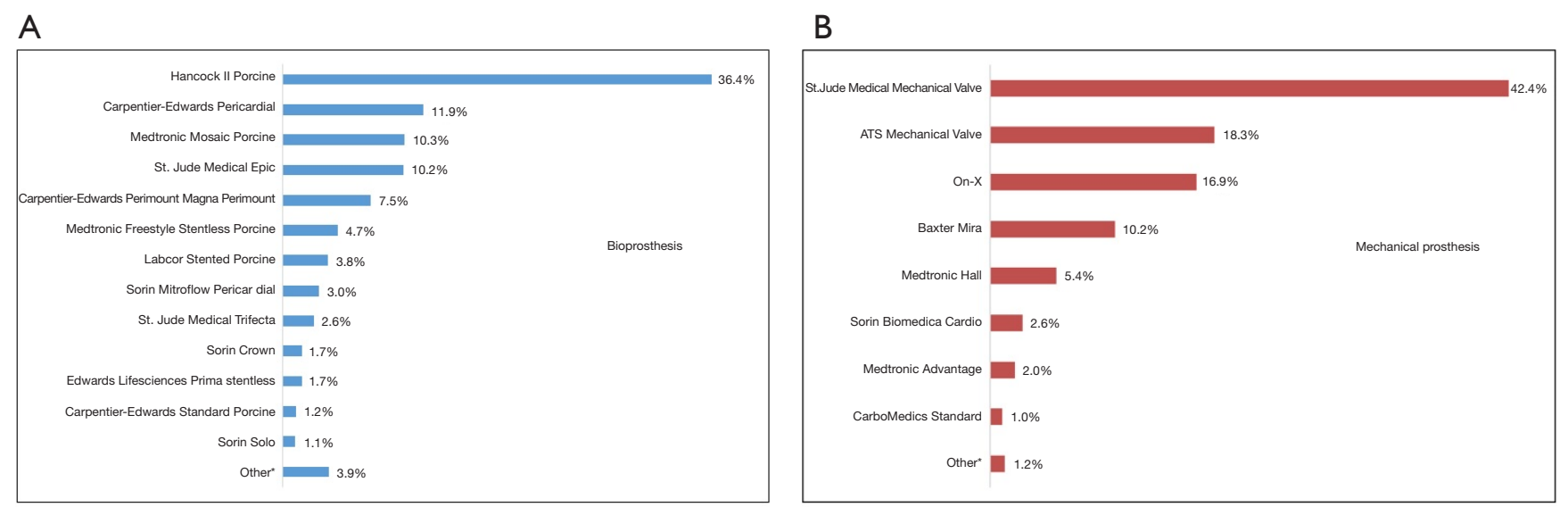

Figure 3 Proportion of all implanted prostheses in each year. (A) Biological prosthesis; (B) mechanical prosthesis. *, all type of prosthesis whose frequency $<1 \%$.

\begin{tabular}{lccccc}
\multicolumn{2}{l}{ 95\% Confidence interval (Odds Ratio scale) } \\
\hline $\begin{array}{l}\text { Odds } \\
\text { Ratio }\end{array}$ & $\mathrm{P}$ & $\begin{array}{l}\text { Lower } \\
\text { bound }\end{array}$ & $\begin{array}{c}\text { Upper } \\
\text { bound }\end{array}$ \\
\hline MALE SEX & 1.474 & $<0.001$ & 1.246 & 1.743 \\
ENDOCARDITIS & 1.174 & 0.404 & 0.806 & 1.709 \\
ATRIAL FIBRILATION & 1.328 & 0.017 & 1.052 & 1.675 \\
PROTHESIS SIZE & 0.888 & $<0.001$ & 0.857 & 0.920 & \\
YEAR OF THE SURGERY & 0.753 & $<0.001$ & 0.710 & 0.798 \\
EUROSCORE I & 0.998 & 0.840 & 0.978 & 1.018 & 0.0 \\
BMI & 1.012 & 0.120 & 0.997 & 1.026 &
\end{tabular}

Figure 4 Multivariate regression model for prosthesis type selection. 
percutaneous procedures, will continue growing (1,2,5,7-10). In the 2017 ACC/AHA guidelines, isolated AVR is still the gold standard treatment for aortic stenosis in low and moderate risk patients (Class I) and is recommended as an alternative to TAVI in high risk patients (Class I) (2). Therefore, TAVI procedures are mainly performed in older groups of patients with a high risk of poor surgical outcomes. In middle-aged patients, presenting lower operative risk and fewer comorbidities, surgical AVR remains the main treatment option (9).

Currently, when replacing the aortic valve, a plethora of prostheses is available $(1-5,7)$, yet the decision comes down to choosing between a BV or an MV (4,11-14). Unfortunately, the selection of prosthesis type is complex. BVs (stented or stentless porcine bioprostheses, stented pericardial prostheses) have the advantage of not requiring lifelong warfarin therapy due to their lower thrombotic risk and significantly decreased risk of bleeding, with the disadvantage of shorter durability (4,11-13,15). MVs (bileaflet or monoleaflet) are partly constructed with pyrolytic carbon, which provides longer durability, but the disadvantages include an increased thromboembolic risk, thus requiring anticoagulation with warfarin and resulting in elevated risk of bleeding $(16,17)$. The most recently updated guidelines point to patient age at the time of implantation as one of the pivotal factors in decision-making process: in younger patients ( $<60$ by ESC/EACTS and $<50$ by AHA/ $\mathrm{ACC}$ ), in whom there is no contraindication for warfarin therapy, a $M V$ is advocated by guidelines $(1,2)$. BVs are recommended in older patients: $>65$ years old in ESC/ EACTS, and $>70$ years in AHA/ACC guidelines (the grey zone being even wider in the American guidelines) $(1,2)$.

Middle-aged (60-70 years old) patients present a particular challenge due to the important considerations of longer life expectancy and potentially more active lifestyle, compared with older patients. The scale of the problem is considerable-our study showed that more than $34 \%$ of all patients undergoing AVR are borderline cases. Moreover, the number of patients operated on in this age group has been steadily increasing, from 607 cases in 2006 to 1,187 in 2015.

Strong recommendations, backed by unequivocal evidence, are lacking for middle-aged patients, and careful decision-making, considering individual patient characteristics and preferences, is warranted in each case. Cardiac surgeons are responsible for guiding the patient through this difficult decision-making process. Our results showed that surgeons implanted BV more often in females, in patients with higher EuroSCORE and patients without atrial fibrillation. The first generation of bioprostheses had increased rates of re-operation due to structural valve deterioration, which is a major obstacle, especially in younger patients. However, newer generations bioprostheses, with good hemodynamic characteristics and novel methods of preservation, achieve durability comparable to mechanical prostheses $(11,13)$. A large metaanalysis including patients between 40 and 70 years old showed that there was no significant difference in survival up to 15 years, based on prosthesis type; the major differences were observed after 20-25 years of observation (13). However, one study has reported non-significant differences in 20 and 25-year outcomes in patients under 60 years old (18). Mortality associated with re-operation is becoming low and acceptable, and may be even lower than mortality associated with major bleeding, resulting from anticoagulation $(12,13)$. Therefore, MVs were chosen more often in patients with $\mathrm{AF}$, already receiving oral anticoagulation.

The factor that has revolutionized the approach to biological valves over the last decade was the development of TAVI. In Poland, the number of TAVI procedures and TAVI-capable centers is constantly growing. While in the early years of the analysed period the increase in the use of BVs might have resulted solely from increasing availability of BV on the Polish market, the role of TAVI might be increasingly important in the more recent years. In authors' opinion, the possibility of avoiding any re-operation by means of percutaneous valve-in-valve procedure in high risk patients is a major factor that caused increased percentage of implanted BVs $(1,2)$.

Compared to BVs, MVs were more often implanted in patients with smaller annulus. MVs present higher index of effective orifice area than BVs, therefore the risk of postoperative patients prosthesis mismatch is lower. Smaller prosthesis size, $\leq 19 \mathrm{~mm}$, which have a higher risk of postoperative prosthesis mismatch, were implanted only in $3.5 \%$ of patients with BVs and in $10.7 \%$ of patients with MVs $(19,20)$. The most common prosthesis size was $23 \mathrm{~mm}$ in both the MVs and BVs groups, and similar to the general AVR group $(7,21)$.

The studied cohort of patients aged 60-70 years in this report was demographically and clinically similar to other AVR cohorts from database studies $(7,21)$.

Our study presents a clinically and practically important trend change in aortic valve surgery in the borderline patients, comprising $1 / 3$ of all individuals operated on for 
aortic valve pathology. An increased rate of BV implantation has been observed in the last decade $(7,21,22)$. However, other databases present higher percentages of implantation procedures in each year in general population, likely a reflection of the aortic valve surgery in the central-eastern Europe. Brown et al. (22) reported a $78.4 \%$ rate of $\mathrm{BV}$ implantation in 2006 and Thourani et al. (7) $83.8 \%$ in 2010 in United States and Dunning et al. (21) 78\% in 2009 in Great Britain and Ireland. However, these data present results of patients in different age groups. It should be also noted that Polish AVR patients are younger, compared to other Western countries. Therefore, in older population groups in other studies, there is also a higher prevalence of BV than observed in the present study. Independently of this difference, it should be noted that the percentage of implanted MVs in Poland is still high.

From nearly ten thousand aortic valve prostheses implanted during the study period in Poland in middle-aged patients, the most common implanted prosthesis was the Hancock II made from porcine aortic valves. The second most implanted prosthesis was the Saint Jude Mechanical Valve. The results showed that in a country where there are 37 cardiac surgery centers, there is significant variety in the different therapeutic valve options, including stented, stentless, sutureless, and mechanical valves (3,23-25). However, we did not assess the effect of valve type on operative outcomes, as the preferred valves change over time, as newer models are released.

In the last 10 years, in-hospital mortality in middleaged patients was $3.3 \%$, and was comparable with results from American or British databases. Advances in pre- and postoperative care have reduced serious postoperative complications $(26,27)$.

\section{Study limitations}

This study has several limitations. Firstly, the information on the EuroSCORE II and STS score is lacking. The EuroSCORE was replaced by EuroSCORE II in 2011. In Poland, different centres replaced their scoring systems at different times. Therefore, we decided to present only EuroSCORE I results. Secondly, in some cases medical data are incomplete (number of missing cases is reported for each variable). However, because of the large number of patients in our database (50,846 cases), these omissions were unlikely to affect the overall study findings. Thirdly, this study has all of the limitations of collection of data from 37 centres.

\section{Conclusions}

Middle-aged patients aged between $60-70$ years old represent more than one-third of all AVR patients. In Poland, the use of valve subtypes has changed over the last ten years due to availability of BVs. In 2016, BVs were implanted in more than $77 \%$ of AVR cases, three times more often than in 2006. In-hospital mortality was 3.3\%.

\section{Acknowledgments}

The KROK investigators include Lech Anisimowicz, MD, $\mathrm{PhD}$; Krzysztof Bartuus, MD, PhD; Andrzej Biederman, MD, PhD; Dariusz Borkowski, MD; Miroslaw Brykczynski, MD, PhD; Pawel Bugajski, MD, PhD; Pawel Cholewinski, MD; Romuald Cichoon, MD, PhD; Marek Cisowski, MD, PhD; Marek Deja, MD, PhD; Antoni Dziatkowiak, MD, PhD; Grzegorz Filip MD, PhD; Tadeusz Gburek, MD; Leszek Gryczko, MD; Ireneusz Haponiuk, MD, Piotr Hendzel, MD, PhD; Tomasz Hirnle, MD, PhD; Stanislaw Jabblonka, MD, PhD; Krzysztof Jarmoszewicz, MD; Jaroslaw Jasinski, MD; Marek Jasinski MD, PhD; Ryszard Jaszewski, MD, PhD; Marek Jemielity, MD, PhD; Ryszard Kalawski, MD, PhD; Boguslaw Kapelak, MD, PhD; Jacek Kaperczak, MD; Maciej A. Karolczak, MD, PhD; Anna Kedziora,, MD; Mariusz Kowalewski, MD; Michal Krejca, $\mathrm{MD}, \mathrm{PhD}$; Wojciech Kustrzycki, MD, PhD; Mariusz Kussmierczyk, MD, PhD; Pawel Kwinecki, MD; Radoslaw Litwinowicz MD, PhD, Bohdan J. Maruszewski MD, PhD; Marcin Maruszewski, MD; Piotr Mazur MD, PhD, Maurycy Missima, MD; Jacek J. Moll, MD, PhD; Wojciech Ogorzeja, MD; Jacek Paja k, MD; Szymon Pawlak, MD; Wojciech Pawliszak, MD; Edward Pietrzyk, MD; Grzegorz Religa, MD; Jan Rogowski, MD, PhD; Jacek Rozanski, MD, PhD; Jerzy Sadowski, MD, PhD; Girish Sharma, MD; Janusz Skalski, MD, PhD; Jacek Skiba, MD, PhD; Ryszard Stanislawski, MD; Janusz-Stazka, MD, PhD; Piotr Stepinski, MD; Kazimierz Suwalski, MD, PhD; Piotr Suwalski MD, PhD; Zdzislaw Tobota, MD; Lukasz Tulecki, MD; Kazimierz Widenka, MD, PhD; Michal Wojtalik, MD, PhD; Stanislaw Wos, MD, PhD; Marian Zembala, $\mathrm{MD}, \mathrm{PhD}$; Michal Oskar Zembala, MD, PhD; and Piotr Zelazny, MD.

Funding: None.

\section{Footnote}

Reporting Checklist: The authors have completed the 
STROBE reporting checklist. Available at http://dx.doi. org/10.21037/jtd-19-3586

Data Sharing Statement: Available at http://dx.doi. org/10.21037/jtd-19-3586

Conflicts of Interest: All authors have completed the ICMJE uniform disclosure form (available at http://dx.doi. org/10.21037/jtd-19-3586). MK serves as an unpaid editorial board member of Fournal of Thoracic Disease from Sep 2018 to Aug 2020. The other authors have no other conflicts of interest to declare.

Ethical Statement: The authors are accountable for all aspects of the work in ensuring that questions related to the accuracy or integrity of any part of the work are appropriately investigated and resolved. The study was conducted in accordance with the Declaration of Helsinki (as revised in 2013). The Polish Society of Cardiothoracic Surgeons approved this project. All data has been anonymized, and the need to obtain individual patient consents has been waived.

Open Access Statement: This is an Open Access article distributed in accordance with the Creative Commons Attribution-NonCommercial-NoDerivs 4.0 International License (CC BY-NC-ND 4.0), which permits the noncommercial replication and distribution of the article with the strict proviso that no changes or edits are made and the original work is properly cited (including links to both the formal publication through the relevant DOI and the license). See: https://creativecommons.org/licenses/by-nc-nd/4.0/.

\section{References}

1. Eacts CS, Germany CH, Rosenhek R, et al. 2017 ESC/ EACTS Guidelines for the management of valvular heart disease The Task Force for the Management of Valvular Heart Disease of the European Society of Cardiology ( ESC ) and the European, 2017:2739-91.

2. Nishimura RA, Otto CM, Bonow RO, et al. 2017 AHA/ ACC Focused Update of the 2014 AHA/ACC Guideline for the Management of Patients with Valvular Heart Disease: A Report of the American College of Cardiology/ American Heart Association Task Force on Clinical Practice Guidelines. Circulation 2017;135:e1159-95.

3. Bartuś K, Litwinowicz R, Kuśmierczyk M, et al. Primary safety and effectiveness feasibility study after surgical aortic valve replacement with a new generation bioprosthesis: One-year outcomes. Kardiol Pol 2018;76:618-24.

4. Filip G, Litwinowicz R, Kapelak B, et al. Mid-term followup after suture-less aortic heart valve implantation. J Thorac Dis 2018;10:6128-36.

5. Bartus K, Sadowski J, Litwinowicz R, et al. Changing trends in aortic valve procedures over the past ten years - From mechanical prosthesis via stented bioprosthesis to TAVI procedures - Analysis of 50,846 aortic valve cases based on a polish national cardiac surgery database. J Thorac Dis 2019;11:2340-9.

6. Zembala M. Main cardiac surgery procedures performed in Poland in 2013 (according to the National Registry of Cardiac Surgery Procedures - KROK, Warsaw, Poland 2014). Kardiochir Torakochirurgia Pol 2014;11:349-52.

7. Thourani VH, Suri RM, Gunter RL, et al. Contemporary real-world outcomes of surgical aortic valve replacement in 141,905 low-risk, intermediate-risk, and high-risk patients. Ann Thorac Surg 2015;99:55-61.

8. Bartus K, Bilewska A, Bochenek M, et al. Five-year Outcomes of Aortic Valve Replacement Using a Bioprosthetic Valve with the Novel RESILIA Tissue: Final Study Results. Struct Hear 2019;3:18.

9. Aroney C. TAVI or Not TAVI—in Low Risk Patients? That Is the Question. Heart Lung Circ 2017;26:749-52.

10. Bartuś K, Sadowski J, Kapelak B, et al. Denervation of nerve terminals in renal arteries: one-year follow-up of interventional treatment of arterial hypertension. Kardiol Pol 2014;72:425-31.

11. Bartus K, Litwinowicz R, Bilewska A, et al. Intermediateterm outcomes after aortic valve replacement with a novel RESILIATM tissue bioprosthesis. J Thorac Dis 2019;11:3039-46.

12. Stone PH. Current Selection of Optimal Prosthetic Aortic Valve Replacement in Middle-Aged Patients. Still Dealer's Choice. J Am Coll Cardiol 2009;54:1869-71.

13. Zhao DF, Seco M, Wu JJ, et al. Mechanical Versus Bioprosthetic Aortic Valve Replacement in Middle-Aged Adults: A Systematic Review and Meta-Analysis. Ann Thorac Surg 2016;102:315-27.

14. Filip G, Litwinowicz R, Kapelak B, et al. Trends in isolated aortic valve replacement in middle-aged patients over the last 10 years: Epidemiology, risk factors, valve pathology, valve types, and outcomes. Kardiol Pol 2019;77:688-95.

15. Klautz RJM, Kappetein AP, Lange R, et al. Safety, effectiveness and haemodynamic performance of a new stented aortic valve bioprosthesis. Eur J Cardiothorac Surg 2017;52:425-31. 
16. Gott VL, Alejo DE, Cameron DE. Mechanical Heart Valves: 50 Years of Evolution. Ann Thorac Surg 2003;76:S2230-9.

17. Tillquist MN, Maddox TM. Cardiac crossroads: Deciding between mechanical or bioprosthetic heart valve replacement. Patient Prefer Adherence 2011;5:91-9.

18. Ruel M, Chan V, Bédard P, et al. Very long-term survival implications of heart valve replacement with tissue versus mechanical prostheses in adults $<60$ years of age. Circulation 2007;116:I294-300.

19. Filip G, Litwinowicz R, Kapelak B, et al. Patientprosthesis mismatch after minimally invasive aortic valve replacement. Kardiol Pol 2018;76:908-10.

20. Filip G, Bartus K, Litwinowicz R, et al. Early clinical outcomes of the surgical treatment of patients with aortic stenosis and small aortic annuli. Kardiochirurgia $i$ Torakochirurgia Pol 2013;10:199-203.

21. Dunning J, Gao H, Chambers J, et al. Aortic valve surgery: marked increases in volume and significant decreases in mechanical valve use--an analysis of 41,227 patients over 5 years from the Society for Cardiothoracic Surgery in Great Britain and Ireland National database. J Thorac Cardiovasc Surg 2011;142:776-82.e3.

22. Brown JM, O'Brien SM, Wu C, et al. Isolated aortic

Cite this article as: Bartus $\mathrm{K}$, Litwinowicz R, Sadowski J, Filip G, Kowalewski M, Suwalski P, Mazur P, Kędziora A, Jasiński M, Deja M, Kuśmierczyk M, Czub P, Zembala M, Jemielity M, Pawlaczyk R, Tobota Z, Maruszewski B, Kapelak B. Bioprosthetic or mechanical heart valves: prosthesis choice for borderline patients?-Results from 9,616 cases recorded in Polish national cardiac surgery registry. J Thorac Dis 2020;12(10):5869-5878. doi: 10.21037/jtd-19-3586 valve replacement in North America comprising 108,687 patients in 10 years: changes in risks, valve types, and outcomes in the Society of Thoracic Surgeons National Database. J Thorac Cardiovasc Surg 2009;137:82-90.

23. Breitenbach I, Wimmer-Greinecker G, Bockeria LA, et al. Sutureless aortic valve replacement with the Trilogy Aortic Valve System: multicenter experience. J Thorac Cardiovasc Surg 2010;140:878-84, 884.e1.

24. Martens S, Sadowski J, Eckstein FS, et al. Clinical experience with the ATS $3 \mathrm{f}$ Enable ${ }^{\circledR}$ Sutureless Bioprosthesis. Eur J Cardiothorac Surg 2011;40:749-55.

25. Englberger L, Carrel TP, Doss M, et al. Clinical performance of a sutureless aortic bioprosthesis: Fiveyear results of the $3 \mathrm{f}$ Enable long-term follow-up study. J Thorac Cardiovasc Surg 2014;148:1681-7.

26. Litwinowicz R, Bartus K, Drwila R, et al. In-hospital mortality in cardiac surgery patients after readmission to the intensive care unit: A single-center experience with 10,992 patients. J Cardiothorac Vasc Anesth 2015;29:570-5.

27. Nicolini F, Agostinelli A, Vezzani A, et al. The evolution of cardiovascular surgery in elderly patient: A review of current options and outcomes. Biomed Res Int 2014;2014:736298. 